Available online at http://iddtonline.info

RESEARCH ARTICLE

\title{
DESIGN AND CHARACTERIZATION OF FLOATING MICROPARTICLES OF A CYCLOOXYGENASE INHIBITOR FOR ARTHRITIS RELATED DISORDERS
}

\author{
Khushbu Akhand*, Mithun Bhowmick, Girijesh Kumar Pandey, Amit Joshi, \\ Balkrishna Dubey \\ TIT College of Pharmacy, Bhopal, India \\ *Corresponding Author's E-mail: khushboo_222@rediffmail.com
}

\begin{abstract}
Floating drug delivery system is one of the novel drug delivery system. Floating drug delivery system such as microspheres have a bulk density less than gastric fluids and thus it remains buoyant in the stomach and thus it remains buoyant on stomach content for long time in the drug releasing process. Hence it is useful for obtaining sufficient bioavailability for long time and effective plasma level. Microspheres provide a constant \& prolonged therapeutic effect which will reduce dosing frequency. Ketoprofen is a nonsteroidal anti-inflammatory drug with well established analgesic and antiarthritic effect by inhibiting the prostaglandin and leukotriene synthesis. It is widely used for the treatment of arthritis related disorders such as rheumatoid arthritis, osteoarthritis, and ankylosing spondylitis. But it requires frequent administration to maintain the plasma drug concentration as the half life of the drug is less and when administered orally. The short half-life and the low single administration dose make ketoprofen a very good candidate for the formulation of controlled release dosage forms such as microspheres. It was also reported that microspheres of nonsteroidal anti-inflammatory drug, reduce gastrointestinal tract irritation.

Keywords: Floating drug delivery system, microspheres, Ketoprofen, rheumatoid arthritis, osteoarthritis, and ankylosing spondylitis
\end{abstract}

\section{INTRODUCTION}

Oral controlled release dosage forms have been developed over the past three decades due to their considerable therapeutic advantages such as ease of administration, patient compliance and flexibility in formulation1. One requisite for successful performance of oral controlled drug delivery system is that drug should have good absorption throughout the gastrointestinal tract, preferably by passive diffusion. These considerations have led to the development of a unique oral controlled release dosage form with Gastroretentive properties. After oral administration, such a dosage form (DF) would be retained in the stomach and releases the drug there in a controlled and prolonged manner, so that the drug could be supplied continuously to its absorption sites in the upper gastrointestinal tract. Gastroretentive dosage forms (GRDFs) can remain in the gastric region for several hours and hence significantly prolong the gastric residence time of drugs. Prolonged gastric retention improves bioavailability, reduces drug waste, and improves solubility of drugs that are less soluble in a high $\mathrm{pH}$ environment. It is also suitable for local drug delivery to the stomach and proximal small intestines. ${ }^{1,3}$ Floating microspheres are gastro-retentive drug delivery systems based on non-effervescent approach. Floating microspheres are spherical empty particles without core. When the microspheres come in contact with gastric fluid, the gel forming polysaccharides and polymers hydrate to form a colloidal gel barrier that controls the rate of fluid penetration into the device and consequent drug release. As the exterior surface of the dosage form dissolves, the gel layer is maintained by the hydration of the adjacent hydrocolloid layer. The air trapped by the swollen polymer lowers the density and confers buoyancy to the microspheres. However, a minimal gastric content needed to allow proper achievement of buoyancy. ${ }^{4-11}$

\section{MATERIALS AND METHODS}

\section{Materials}

Ketoprofen, Hydroxypropyl methylcellulose, Ethyl cellulose, Eudragit S-100, Dichloro methane, Methanol.

\section{Methods}

Preparation of Floating Microspheres of Ketoprofen ${ }^{1-5}$

Floating microspheres were prepared by the solvent evaporation method. Various concentration of polymer in dichloromethane were mixed well with $500 \mathrm{mg}$ of the Ketoprofen with different proportion of polymer as shown in Table were dissolved in dichloromethane $(5 \mathrm{ml})$ and this pasty, flowable mass was introduced into $50 \mathrm{ml}$ of aqueous saline phase containing $0.04 \%(20 \mathrm{mg})$ polyvinyl alcohol (PVA) and 10\% (5 ml) methanol. The system is stirred using propeller at $300 \mathrm{rpm}$ at room temperature for 2-3 hr. The drug loaded floating microspheres formed were filtered, washed and dried in a hot air oven at $60^{\circ} \mathrm{C}$. 
Formulation Design

Table1: Formulation of Ketoprofen Floating Microspheres

\begin{tabular}{|c|c|c|c|}
\hline Formulation code & Eudragit S-100 & Ethyl cellulose & Dichloromethane:Methanol \\
\hline F1 & $\mathbf{0 . 5}$ & - & $1: 1$ \\
\hline F2 & $\mathbf{1 . 0}$ & - & $1: 1$ \\
\hline F3 & $\mathbf{1 . 5}$ & - & $1: 1$ \\
\hline F4 & - & $\mathbf{0 . 5}$ & $1: 1$ \\
\hline F5 & - & $\mathbf{1 . 0}$ & $1: 1$ \\
\hline F6 & - & $\mathbf{1 . 5}$ & $1: 1$ \\
\hline
\end{tabular}

\section{EVALUATION OF FLOATING MICROSPHERES}

\section{Percentage Yield ${ }^{6}$}

The prepared microspheres of all batches were accurately weighed. The measured weight of prepared microspheres was divided by the total amount of all the excipients and drug used in the preparation of the microspheres, which give the total percentage yield of floating microspheres. It was calculated by using following equation,

$$
\% \text { Yield }=\frac{\text { Actual weight of product }}{\text { Total weight of excipients and drug }} \times 100
$$

\section{Micromeritic Studies ${ }^{6,7,8}$}

The prepared microspheres are characterized by their micromeritic properties, such as microsphere size, tapped density, Carr's compressibility index, Hausner's ratio and angle of repose.

\section{Bulk Density}

The bulk density is defined as the mass of powder divided by bulk volume. The bulk density was calculated by dividing the weight of the samples in grams by the final volume in $\mathrm{cm}^{3}$

$$
\text { Bulk density }=\frac{\text { Mass of microspheres }}{\text { Volume of microspheres before tapping }}
$$

\section{Tapped Density}

Tapped density is the volume of powder determined by tapping by using a measuring cylinder containing weighed amountof sample. The cylinder containing known amount of microspheres was tapped for about 1 minute on a tapped density apparatus until it gives constant volume.

Tapped density $=$

$$
\text { Mass of microspheres }
$$

Volume of microspheres after tapping

\section{Carr's Compressibility Index}

This is an important property in maintaining uniform weight. It is calculated using following equation,

$$
\% \text { Compressibility Index }=\frac{\text { Tapped density }- \text { Bulk density }}{\text { Tapped density }} \times 100
$$

Lower the compressibility values indicate better flow.
Table 2: Relationship between \% Compressibility and Flowability

\begin{tabular}{|c|c|}
\hline \% Compressibility & Flowability \\
\hline $5-15$ & Excellent \\
\hline $12-16$ & Good \\
\hline $18-21$ & Fair to passable \\
\hline $23-35$ & Poor \\
\hline $33-38$ & Very poor \\
\hline$>40$ & Extremely poor \\
\hline
\end{tabular}

\section{Hausner ratio}

A similar index like percentage compressibility index has been defined by Hausner. Values less than 1.25 indicate good flow, where as greater than 1.25 indicates poor flow. Added glidant normally improve flow of the material under study. Hausner's ratio can be calculated by formula,

$$
\text { Hausner's ratio }=\frac{\text { Tapped density }}{\text { Bulk density }} \times 100
$$

\section{Angle of Repose ( $\theta)$}

Good flow properties are critical for the development of any pharmaceutical tablet, capsules or powder formulation. It is essential that an accurate assessment of flow properties be made as early in the development process as possible so that an optimum formulation can be quickly identified. Interparticle forces between particles as well as flow characteristics of powders are evaluated by angle of repose. Angle of repose is defined as the maximum angle possible between the surface and the horizontal plane.

The angle of repose of each powder blend was determined by glass funnel method. Powders were weighed accurately and passed freely through the funnel so as to form a heap. The height of funnel was soadjusted that the tipof the funnel just touched the apex of the heap. The diameter of the powder cone so formed was measured and the angle of repose was calculated using the following equation,

$$
\begin{aligned}
& \tan \Theta=h / r \\
& \Theta=\tan ^{-1}(h / r)
\end{aligned}
$$

Where, $\theta=$ angle of repose

$\mathrm{h}=$ height of the pile and,

$r=$ radius of the powder cone respectively.

Angle of repose affects particle size distribution, as larger the particle size, it will flow freely and vice-versa. It is a 
helpful parameter to monitor quality of powdered or granular pharmaceutical formulations. For good flowing materials the, angle of repose should be less than $30^{\circ}$.

Table 3: Relationship between Angle of Repose and Flowability

\begin{tabular}{|c|c|}
\hline Angle of Repose & Flowability \\
\hline$<25$ & Excellent \\
\hline $25-30$ & Good \\
\hline $30-40$ & Passable \\
\hline$>40$ & Very poor \\
\hline
\end{tabular}

\section{Particle Size Determination ${ }^{10,12}$}

Microsphere size was determined by using an optical microscope under regular polarized light, and the mean microsphere size was calculated by measuring 100 particles with the help of a calibrated ocular micrometer.

\section{Morphological Study using SEM ${ }^{13,18}$}

The morphological study was carried out by Scanning Electron Microscope (SEM). Microspheres were scanned and examined under Electron Microscope HITACHI SU 1500, Japan connected with Fine coat, JEOL JFC-1100E Ion sputter. The sample was loaded on copper sample holder and sputter coated with carbon followed by Gold.

\section{Drug Loading and Drug Entrapment ${ }^{17,18,19}$}

Floating microspheres were dissolved in a minimum amount of methanol and drug was extracted into $0.1 \mathrm{~N}$ hydrochloric acid by evaporating methanol. The solution was filtered through whatman filter paper, diluted suitably and analyzed for drug content spectrophotometrically at $254 \mathrm{~nm}$ using $0.1 \mathrm{~N}$ hydrochloric acid as blank. The amount of drug loaded and entrapped in the microspheres was calculated by the following formulas:

$$
\begin{aligned}
& \% \text { Drug loading }=\frac{\text { Weight of the drug loaded in the microspheres (DC) }}{\text { Total weight of the microspheres }} \times 100 \\
& \% \text { Drug entrapment }=\quad \frac{\text { Amount of drug actually present }(D C)}{\text { Theoretical drug load expected }} \times 100
\end{aligned}
$$

\section{In vitro Buoyancy Study ${ }^{15,16}$}

Microspheres (300mg) were spread over the surface of a USP dissolution apparatus type II filled with $900 \mathrm{ml}$ of 0.1 $\mathrm{N} \mathrm{HCl}$ (pH-1.2) containing $0.02 \%$ tween 80. The medium was agitated with a paddle rotating at $100 \mathrm{rpm}$ for $12 \mathrm{~h}$. The floating and the settled portions of microspheres were recovered separately. The microspheres were dried and weighed. Buoyancy percentage was calculated as the ratio of the mass of the microspheres that remained floating and the total mass of the microspheres.

$$
\text { Buoyancy }(\%)=\frac{W_{f}}{W_{f}+W_{s}} \times 100
$$

Where $\mathrm{W}_{\mathrm{f}}$ and $\mathrm{W}_{\mathrm{s}}$ are the weights of the floating and settled micropshers, respectively. All the determinations were made in triplicate.

\section{In-vitro Release Study ${ }^{14,15,16}$}

The drug release study was performed for microsphere containing quantity equivalent to $150 \mathrm{mg}$ of ketoprofen by using USP dissolution apparatus Type I in $900 \mathrm{ml}$ of $0.1 \mathrm{~N}$ $\mathrm{HCl}$ dissolution media (pH-1.2) at $100 \mathrm{rpm}$ and $37^{\circ} \mathrm{C}$ temperature. $10 \mathrm{ml}$ of sample was withdrawn at predetermined time interval for 12 hours and same volume of fresh medium was replaced to maintained sink condition. Withdrawn samples were assayed spectrophotometrically at $254 \mathrm{~nm}$. Drug release was also performed for pure drug.

\section{Release Kinetics}

The matrix systems were reported to follow the Peppas release rate and the diffusion mechanism for the release of the drug. To analyse the mechanism for the release and release rate kinetics of the dosage form, the data obtained was fitted in to, Zero order, First order, Higuchi matrix, Peppas. In this by comparing the r-values obtained, the best-fit model was selected.

\section{RESULT AND DISCUSSION \\ PREFORMULATION STUDIES}

Organoleptic Property: Physical appearance of drug was examined by various organoleptic properties.

\section{Table 4: Organoleptic Properties}

\begin{tabular}{|c|c|}
\hline Organoleptic Property & Observation \\
\hline Color & White or almost white \\
\hline Odor & Odorless \\
\hline Taste & Tasteless \\
\hline State & Fine to granular powder \\
\hline
\end{tabular}

Melting Point: Melting point of the Ketoprofen was found out to be $96^{\circ} \mathrm{C}$ by capillary fusion method

Solubility: Ketoprofen was found to be freely soluble in ethanol (95\%), in chloroform, and in ether, practically insoluble in water. Adjusting $\mathrm{pH}$ to a higher value can solubilize Ketoprofen, as solubility increase at $\mathrm{pH}$ values above its pKa.

Table 5: Solubility

\begin{tabular}{|c|c|c|}
\hline S.NO. & SOLVENT & SOLUBILITY \\
\hline 1 & Water & - \\
\hline 2 & Phosphate buffer 7.4 & ++ \\
\hline 3 & $0.1 \mathrm{~N} \mathrm{HCL}$ & + \\
\hline 4 & $0.1 \mathrm{~N} \mathrm{NaOH}$ & + \\
\hline 5 & Methanol & ++ \\
\hline 6 & Ethanol & ++ \\
\hline 7 & Chloroform & ++ \\
\hline 8 & Dichloromethane & ++ \\
\hline 9 & Acetone & ++ \\
\hline \multicolumn{2}{|c|}{ Practically insoluble (-) slightly soluble (+) soluble (++) } \\
\hline
\end{tabular}


Development of Calibration Curve for Ketoprofen ( $\lambda \max )$

The absorption maximum ( $\lambda \max )$ is determined as $254 \mathrm{~nm}$.

\section{Fourier Transform Infrared Spectroscopy:}

On comparing the IR spectra of the reference spectra given in Indian Pharmacopoeia (1996) and IR spectra of the pure drug, no major differences were observed in the characteristic absorption peak pattern, which shows that the drug obtained was pure.

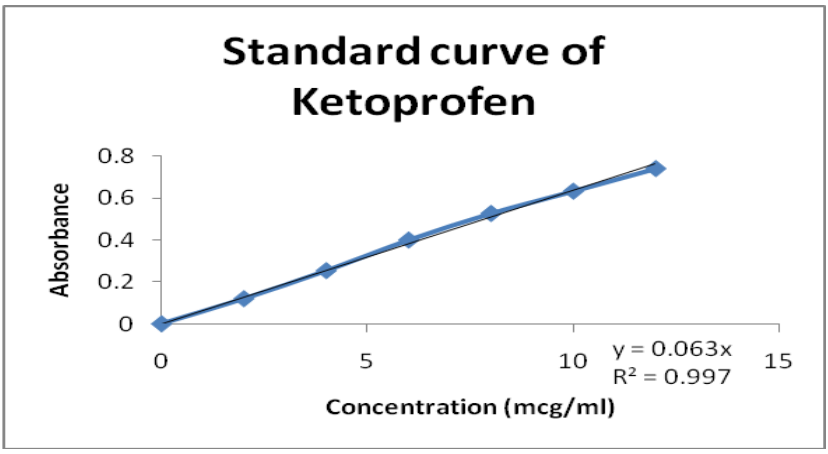

Figure 1: Calibration Curve for Ketoprofen ( $\lambda$ max)

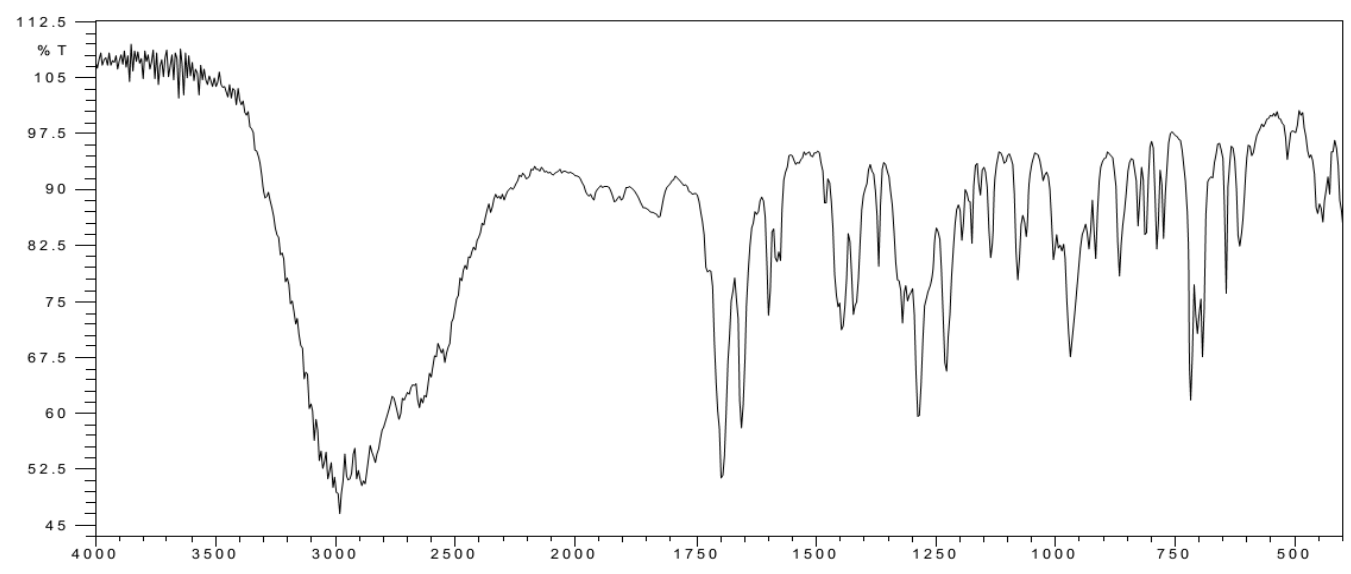

Figure 2: FTIR spectra of Ketoprofen

Table 6: FTIR absorption peak values of Ketoprofen

\begin{tabular}{|c|c|c|}
\hline \multirow{4}{*}{ Drug } & $\begin{array}{c}\text { Functional } \\
\text { group }\end{array}$ & $\begin{array}{c}\text { Characteristics absorption } \\
\text { peak cm }\end{array}$ \\
\hline \multirow{4}{*}{ Ketoprofen } & OH str & 3000.50 \\
\cline { 2 - 3 } & CH str & 2900.01 \\
\cline { 2 - 3 } & CHdf & 1290.23 \\
\cline { 2 - 3 } & $\mathrm{C}=\mathrm{O}$ str & 1650 \\
\cline { 2 - 3 } & $\mathrm{Ar}-\mathrm{H}$ & 710 \\
\hline
\end{tabular}

\section{Interference of Additives/Compatibility Testing}

The results of UV spectroscopic analysis indicated that there was no chemical interaction between the drug and the additives as the respective formulation (Drug and Polymer combination) exhibited absorption nearly similar to those of the pure drug sample.

Table 7: Interference of Additives/Compatibility Testing

\begin{tabular}{|c|c|c|c|c|}
\hline \multirow{2}{*}{ Formulation } & \multicolumn{2}{|c|}{ Absorbance of solutions } & \multirow{2}{*}{$\begin{array}{c}\text { Interference } \\
\text { Yes / No }\end{array}$} \\
\cline { 2 - 5 } & Polymer blend with drug & Placebo & Pure drug & No \\
\hline Ketoprofen-eudragit s100 & 0.635 & 0.003 & 0.633 & No \\
\hline Ketoprofen-Ethyl cellulose & 0.636 & 0.001 & 0.633 & \\
\hline
\end{tabular}

\section{Evaluation of Microspheres}

\section{Percentage yield}

The percentage practical yield slightly decreased as the polymer ratio increased. The results of all formulations F1to F6 of floating microsphere are shown in Table 8. 
Table 8: Percentage yield

\begin{tabular}{|c|c|c|c|}
\hline Formulation Code & Theoretical Weight $(\mathbf{g m})$ & Practical Yield (gm) & Percentage Yield (\%) \\
\hline F1 & 1.0 & 0.731 & 73.1 \\
\hline F2 & 1.5 & 0.983 & 65.53 \\
\hline F3 & 2.5 & 1.509 & 60.36 \\
\hline F4 & 1.0 & 0.726 & 72.6 \\
\hline F5 & 1.5 & 1.901 & 60.06 \\
\hline F6 & 2.5 & 1.414 & 56.56 \\
\hline
\end{tabular}

\section{Micromeritic Properties}

The results of all formulations F1 to F6 of Floating microsphere are shown in Table..., which were evaluated for variable parameters such as bulk density, tapped density, \% Compressibility index, Hausner's ratio and angle of repose.

The \% Compressibility index was in the range of 11.4417.55 for all the formulations F1 to F6 indicating good flow property. The value of Hausner's ratio for the all formulation F1to F6 was below 1.25 which indicates good flow property.

The values of angle of repose for formulations F1to F5 was found to be in the range of $25^{\circ}-30^{\circ}$ which indicated the good flow potential and the formulation F6 showed below $25^{\circ}$ which indicated excellent flow.

Table 9: Micromeritic Properties

\begin{tabular}{|c|l|l|}
\hline $\begin{array}{c}\text { Formulation } \\
\text { Code }\end{array}$ & $\begin{array}{c}\text { Bulk Density } \\
\left(\mathbf{g} / \mathbf{c m}^{\mathbf{3}}\right)\end{array}$ & $\begin{array}{c}\text { Tapped Density } \\
\left(\mathbf{g} / \mathbf{c m}^{\mathbf{3}}\right)\end{array}$ \\
\hline F1 & 0.144 & 0.154 \\
\hline F2 & 0.447 & 0.518 \\
\hline F3 & 0.513 & 0.600 \\
\hline F4 & 0.402 & 0.473 \\
\hline F5 & 0.445 & 0.533 \\
\hline F6 & 0.462 & 0.563 \\
\hline
\end{tabular}

Table 10: Micromeritic Properties

\begin{tabular}{|c|l|l|l|}
\hline $\begin{array}{c}\text { Formulation } \\
\text { Code }\end{array}$ & \multicolumn{1}{|c|}{$\begin{array}{c}\text { Compressibility Index } \\
(\boldsymbol{\%})\end{array}$} & \multicolumn{1}{|c|}{ Hausner's Ratio } & \multicolumn{1}{|c|}{$\begin{array}{c}\text { Angle of Repose } \\
(\boldsymbol{\theta})\end{array}$} \\
\hline F1 & 11.44 & 1.120 & $25^{\circ} 15^{\prime}$ \\
\hline F2 & 13.23 & 1.144 & $26^{\circ} 10^{\prime}$ \\
\hline F3 & 14.19 & 1.157 & $26^{\circ} 40^{\prime}$ \\
\hline F4 & 14.61 & 1.162 & $27^{\circ} 10^{\prime}$ \\
\hline F5 & 16.10 & 1.183 & $27^{\circ} 90^{\prime}$ \\
\hline F6 & 17.55 & 1.204 & $28^{\circ} 40^{\prime}$ \\
\hline
\end{tabular}

\section{Particle Size Analysis}

Average particle size of microspheres as determined by optical microscopy by using stage micrometer and ocular micrometer are shown in Table.

With increase in Eudragit S-100 and Ethyl cellulose concentration in the microspheres from F1 to F3 and F4 to F6, the particle size of microspheres increases respectively. This is because the viscosity of the polymer solution increases with increasing polymer concentration, which in turn decreases the stirring efficiency. The polymer rapidly precipitates leading to hardening and avoiding further particle size reduction during solvent evaporation. The average particle size of Eudragit S-100 was greater due to the greater viscosity than Ethyl cellulose.

Table 11: Particle Size Analysis

\begin{tabular}{|c|c|}
\hline Formulation Code & Average Particle Size $(\boldsymbol{\mu m})$ \\
\hline F1 & 65.16 \\
\hline F2 & 75.45 \\
\hline F3 & 95.10 \\
\hline F4 & 52.46 \\
\hline F6 & 61.30 \\
\hline
\end{tabular}

\section{Scanning Electron Microscopy}

Morphology of microspheres was examined by scanning electron microscopy. The view of the microspheres showed a hollow spherical structure with a smooth surface morphology and exhibited a range of sizes within each batch

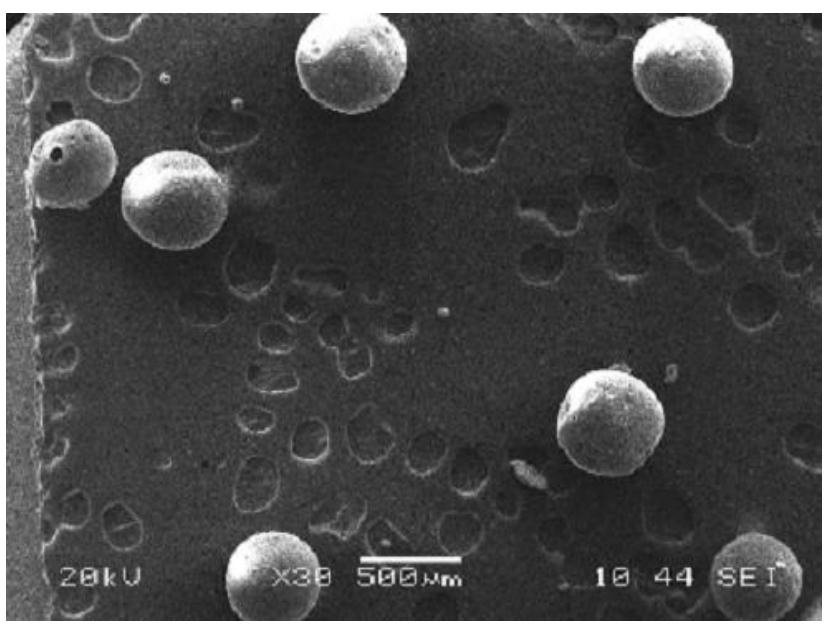

Figure 3: SEM of Microspheres 


\section{Drug Loading and Drug Entrapment}

The values of \%drug loading and \% entrapment efficiency are shown in Table. As the polymer concentration was increased the \% drug loading decreased and \%entrapment efficiency was increased due to increase in the viscosity of the solution. This can be attributed to the permeation characteristics of each polymer used, that could facilitate the diffusion of part of entrapped drug to the surrounding medium during preparation of floating microspheres.

\section{In vitro Buoyancy Study}

The microspheres prepared by using higher polymer concentrations shows high density. So the microspheres having higher polymer concentrations were less buoyant than those with lower polymers concentrations. Ketoprofen-Eudragit S-100 microspheres showed lesser buoyancies when compared to the Ketoprofen -Ethyl cellulose microspheres because of the lesser number of pores in the former. The formulation F4 showed highest buoyancy of $87 \%$ while the formulation F3 showed the least buoyancy of $76 \%$.

Table 12: Drug Loading and Drug Entrapment

\begin{tabular}{|c|c|c|}
\hline $\begin{array}{c}\text { Formulation } \\
\text { Code }\end{array}$ & $\begin{array}{c}\text { \% Drug } \\
\text { Loading }\end{array}$ & $\begin{array}{c}\text { \% Drug } \\
\text { Entrapment }\end{array}$ \\
\hline F1 & 37.16 & 75.52 \\
\hline F2 & 26.41 & 81.38 \\
\hline F3 & 17.18 & 89.89 \\
\hline F4 & 38.44 & 77.78 \\
\hline F5 & 27.30 & 83.88 \\
\hline F6 & 17.60 & 92.20 \\
\hline
\end{tabular}

Table 13: In vitro Buoyancy Study

\begin{tabular}{|c|c|c|c|}
\hline $\begin{array}{c}\text { Formulation } \\
\text { Code }\end{array}$ & $\begin{array}{c}\text { Weight of Floating } \\
\text { Microspheres Taken } \\
\text { (mg) }\end{array}$ & $\begin{array}{c}\text { Weight of } \\
\text { Microspheres } \\
\text { Floated (mg) }\end{array}$ & $\begin{array}{c}\text { Percent } \\
\text { Buoyancy }\end{array}$ \\
\hline F1 & 300 & 250 & 83.33 \\
\hline F2 & 300 & 239 & 79.66 \\
\hline F3 & 300 & 228 & 76 \\
\hline F4 & 300 & 261 & 87 \\
\hline F6 & 300 & 252 & 84 \\
\hline
\end{tabular}

\section{In vitro drug release studies}

Dissolution studies on all the six formulations of Ketoprofen floating microspheres were carried out using a USP dissolution apparatus Type I. $0.1 \mathrm{~N} \mathrm{HCl}(\mathrm{pH} 1.2)$ was used as the dissolution medium. The cumulative drug release significantly decreased with increase in polymer concentration. The increased density of the polymer matrix at higher concentrations results in an increased diffusional pathlength. This may decrease the overall drug release from the polymer matrix. Furthermore, smaller microspheres are formed at a lower polymer concentration and have a larger surface area exposed to dissolution medium, giving rise to faster drug release.

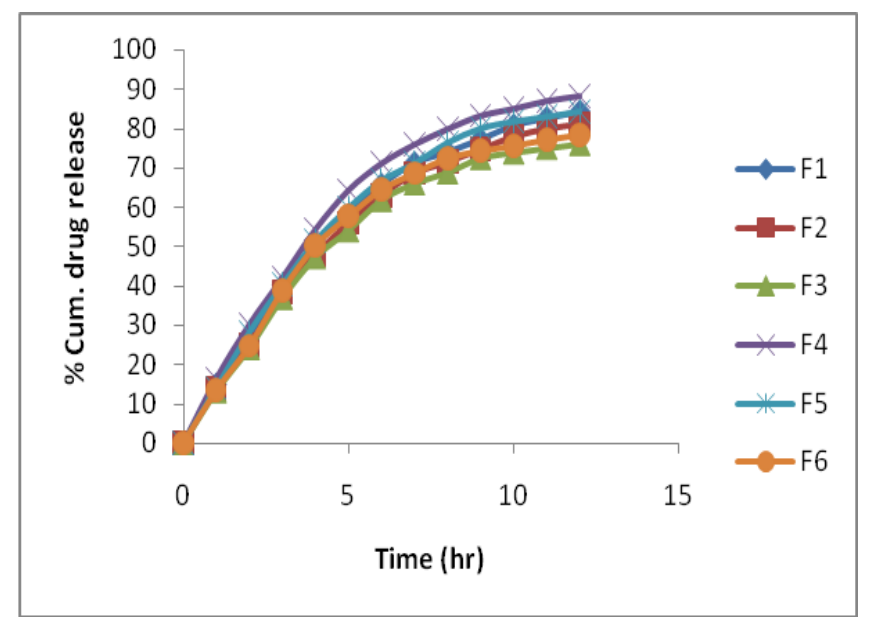

Figure 4: Zero order release kinetics
First order release kinetics data

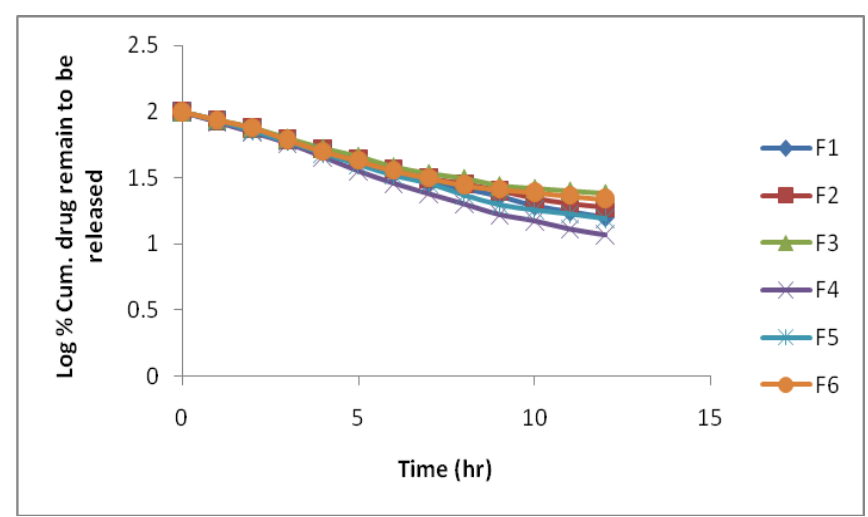

Figure 5: First order release kinetics

Higuchi matrix release kinetics data

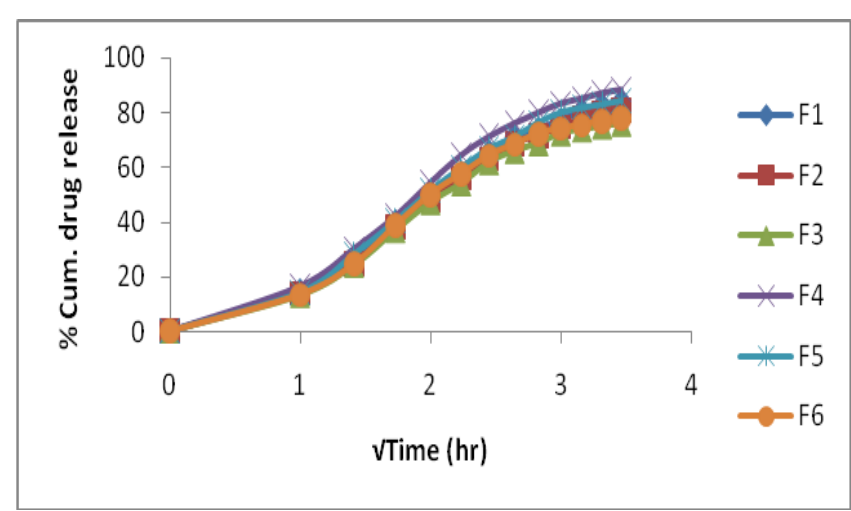

Figure 6: Higuchi matrix release kinetics 


\section{Peppas release kinetics data}

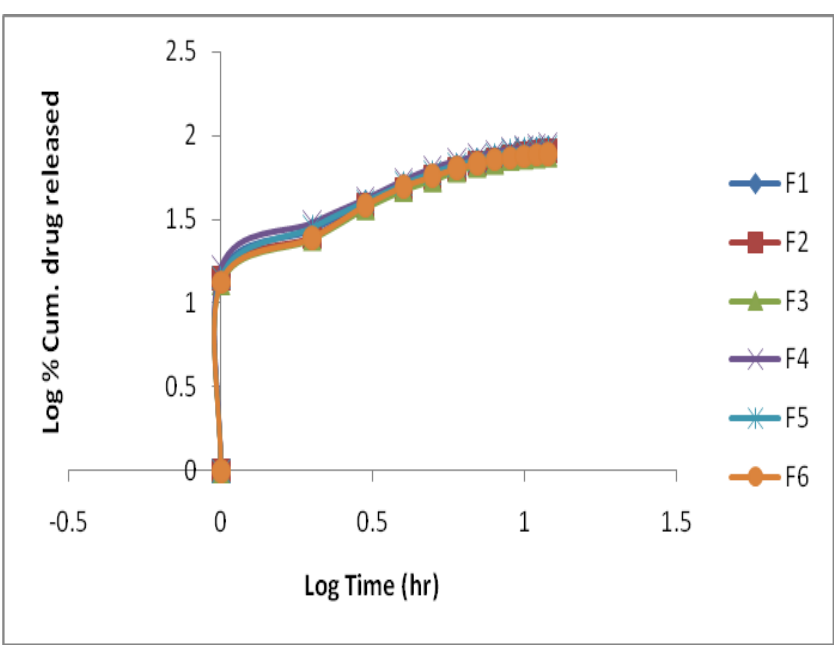

Figure 7: Peppas release kinetics

\section{Release Kinetics}

The curve fitting results of the release rate profiles of the designed formulation are shown in the Figures ... which gave an idea on the release rate and the mechanism of release. The values were compared with each other for model and drug equation as shown in Table ..based on the highest regression values ( $r$ ), fitting of the release rate data to the various models revealed that the all the formulations follows first order release kinetics. The Peppas model is widely used when the release mechanism is not well known or when more than one type of release phenomenon could be involved. ' $n$ ' value could be used to characterize different release mechanisms. The $\mathrm{n}$ values for formulations $\mathrm{F} 1$ to $\mathrm{F} 6$ ranged from 0.605 to 0.741 , indicating that the release mechanism was non-Fickian or anomalous release $(0.5<\mathrm{n}<1)$. Based on the $\mathrm{n}$ values, F1 to F6, drug release from microsphere were controlled by polymer relaxation (erosion) as well as diffusion.

Table 14: Release Kinetics

\begin{tabular}{|c|c|c|c|c|c|c|}
\hline \multirow{2}{*}{$\begin{array}{l}\text { Formulation } \\
\text { code }\end{array}$} & \multicolumn{4}{|c|}{ Correlation coefficient of Model fitting $\left(\mathbf{R}^{2}\right)$} & \multirow{2}{*}{$\begin{array}{l}\text { 'n' values for } \\
\text {-Peppas }\end{array}$} & \multirow{2}{*}{$\begin{array}{l}\text { Best fit } \\
\text { model }\end{array}$} \\
\hline & Zero order & First order & Higuchi matrix & Peppas kinetics & & \\
\hline F1 & 0.916 & 0.991 & 0.978 & 0.968 & 0.685 & First order \\
\hline F2 & 0.921 & 0.986 & 0.976 & 0.969 & 0.713 & First order \\
\hline F3 & 0.892 & 0.971 & 0.969 & 0.959 & 0.605 & First order \\
\hline F4 & 0.895 & 0.989 & 0.973 & 0.964 & 0.653 & First order \\
\hline F5 & 0.889 & 0.983 & 0.974 & 0.961 & 0.712 & First order \\
\hline F6 & 0.887 & 0.984 & 0.964 & 0.950 & 0.741 & First order \\
\hline
\end{tabular}

\section{CONCLUSION}

Floating microspheres have a bulk density less than gastric fluids and thus it remains buoyant in the stomach without affecting gastric emptying rate for a prolonged period of time. While the system is floating on the gastric contents, the drug is released slowly at the desired rate from the system. Also floating microspheres provide a constant and prolonged therapeutic effect which will reduce dosing frequency.

In the present study, floating microspheres of ketoprofen were prepared using different polymers like ethyl cellulose and eudragit by solvent evaporation diffusion method.

The surface morphology of the prepared floating microspheres was studied using scanning electron microscopy. The prepared floating microspheres also characterized by FTIR spectroscopy and UV-Spectroscopy was used to find out any chemical interaction between
Ketoprofen and polymers used. The prepared floating microspheres were evaluated for particle size,percentage yield, drug entrapment efficiency, micromeritic properties (like bulk density, tapped density, hausners ratio, angle of repose, compressibility index) in vitro buoyancy and in vitro drug release study and as described in chapter-4. The results indicated that the significant effect was observed of increased polymer concentration, on said parameters in each case.

The details of results are given in chapter-5. The mean particle size of the microspheres significantly increased with increase in polymer concentration. Micromeritic study suggested excellentflow properties of prepared microspheres. The in vitro release was in the following order: $\mathrm{F} 4>\mathrm{F} 5>\mathrm{F} 1>\mathrm{F} 2>\mathrm{F} 6>\mathrm{F} 3$. 


\section{REFERENCES}

1. Garg R, Gupta GD. Progress in Controlled Gastroretentive delivery systems. Tropical Journal of Pharmaceutical Research. 2008; 7:1055-1056.

2. Patil JM, Hirlekar RS, Gide PS and Kadam VJ. Trends in Floating Drug Delivery Systems. Journal of Scientific and Industrial Research. 2006; 65:11-21.

3. Furquan Khan N, Mohamed Dehghan HG. Gastroretentive drug delivery systems: A patent perspective. International Journal of Health research. 2009; 2:23-44

4. Shweta Arora, Javed Ali, Alka Ahuja, Roop Khar K and Sanjula Babooota. Floating Drug Delivery Systems: A Review. AAPS Pharm Sci Tech. 2005; 6: E372-390.

5. Vyas SP. Khar. "Targeted and Controlled Drug Delivery Novel Carrier System”, Ist Ed., CBS Publishers and Distributors. 2002 ; 417-54.

6. Tanwar YS. Floating Microspheres: Development, Charecterisation and Applications. Pharmainfo.net.

7. Kumaresh Soppimath S, Anandrao Kulkarni R and Tejraj Aminabhavi M. Development of Hollow Microspheresas Floating Controlled-Release Systems. For Cardiovascular Drugs: Preparation and Release Characteristics. Drug Development and Industrial Pharmacy. 2001; 27:507-515.

8. Streubel A, Siepmann J and Bodmeier R. Multiple unit gastroretentive drug delivery systems: A new preparation method for low density microparticles. . J.Microencapsulation.2003; 20 : 329-347.

9. Jain AK, Jain CP, Tanwar YS and Naruka PS. Formulation, characterization and in-vitro evaluation of floating microspheres of Famotidine as a gastroretentive dosage form. Asian journal of pharmaceutics. 2009:222-226.

10. Patel A, Ray S, Thakur RS. Invitro evaluation and optimization of controlled release floating drug delivery system of metformin hydrochloride. DARU14. 2006; 2, 57-64.

11. Patil HS, Patil MP, Bharat Tekade W, Vinod Thakare M, Vijay Patil M. Formulation and In-Vitro Evaluation of Floating
Microspheres of Acyclovir. Arch Pharm Sci \& Res .2009; 1:194 198.

12. Singh, B.N., Kim, K.H.; Floating drug delivery system; An approach to oral controlled drug delivery via gastric retention. J. Control Release, 2000; 63 (3): 235-259.

13. Sato. Y., Kawashima Y., Takeuchi, N.; Physicochemical Properties to determine the buoyancy of hollow microspheres (microballoons) prepared by the emulsion solvent diffusion method, Eur. J. Pharm. \& Biopham., 2003; 55: 297-304.

14. El-Kamal, A.H., Sokar, M.S., Al-Gamal, S.S., Naggar, V.F.; Preparation \& Evaluation of Ketoprofen floating oral delivery system, Int. J. Pharm., 2001; 220: 13-21.

15. Sato, Y., Kawashima, Y., Takeuchi, H.; Invitro evaluation of floating drug releasing behaviour of hollow microspheres (microballoons) prepared by emulsion solvent diffusion method, Eur. J. of Pharm. \& Biopharm, 2004; 57: 235-243.

16. Patel V.F., Patel N.M., Yeole P.G.; Studies on formulation \& Evaluation of Ranitidine Floating tablet, Indian J. Pharm. Sci., 2004; 5(2),34,1-6

17. Kale R.D., Tayade, P.; A Multiple unit floating drug delivery system of piroxicam using eudragit polymer, Indian J. Pharm. Sci., 2007; 67 (1): 120-123.

18. Dave B.S., Amin, A. F., Patel, M. M.; Gastro-retentive Drug Delivery System of Ranitidine Hydrochloride: formulation and in vitro evaluation, AAPS Pharm Sci. Tech., 2004; 5(2): 34.

19. Muthusamy, K., Govindatuzan. G.; Preparation \& Evaluation of Lansoprazole floating Micropellets, Indian. J.Pharm. Sci., 2005; 67(1): 75-79.

20. Streubel, A., Siepmann, J., Bodmeier, R.T.; Floating matrix tablets bared on low density foam powder effects of formulation, processing on drug release, Eur. J. Pharm. Sci.,2003; 13: 37-45.

21. Sweetman SC. Martindale, The complete drug reference. $33^{\text {rd }}$ ed. Pharmaceutical press; 2002.

22. British Pharmacopoeia. 2007, Vol. II, p.1197-1199 